Research Article

\title{
Sox Genes Show Spatiotemporal Expression during Murine Tongue and Eyelid Development
}

\author{
Ryuichi Ishikawa, ${ }^{1}$ Maiko Kawasaki, ${ }^{1}$ Katsushige Kawasaki, ${ }^{1,2}$ Akane Yamada, ${ }^{1}$ \\ Supaluk Trakanant, ${ }^{1}$ Fumiya Meguro, ${ }^{1}$ Atsushi Kitamura, ${ }^{1}$ Takehisa Kudo, \\ Takeyasu Maeda, ${ }^{2}$ and Atsushi Ohazama $\mathbb{D}^{1}$ \\ ${ }^{1}$ Division of Oral Anatomy, Department of Oral Life Science, Niigata University Graduate School of Medical and Dental Sciences, \\ Niigata, Japan \\ ${ }^{2}$ Research Center for Advanced Oral Science, Department of Oral Life Science, Niigata University Graduate School of Medical \\ and Dental Sciences, Niigata, Japan
}

Correspondence should be addressed to Atsushi Ohazama; atsushiohazama@dent.niigata-u.ac.jp

Received 21 June 2018; Revised 3 August 2018; Accepted 27 August 2018; Published 9 October 2018

Academic Editor: Tommaso Lombardi

Copyright (c) 2018 Ryuichi Ishikawa et al. This is an open access article distributed under the Creative Commons Attribution License, which permits unrestricted use, distribution, and reproduction in any medium, provided the original work is properly cited.

\begin{abstract}
The tongue is a critical organ, involved in functions such as speaking, swallowing, mastication, and degustation. Although Sox genes are known to play critical roles in many biological processes, including organogenesis, the expression of the Sox family members during tongue development remains unclear. We therefore performed a comparative in situ hybridization analysis of 17 Sox genes (Sox1-14, 17, 18, and 21) during murine tongue development. Sox2, 4, 6, 8, 9, 10, 11, 12, and 21 were found to be expressed in the tongue epithelium, whereas Sox2, 4-6, 8-11, 13, and 21 showed expression in the mesenchyme of the developing tongue. Expression of Sox 1, 4, 6, 8-12, and 21 were observed in the developing tongue muscle. Sox 5 and 13 showed expression only at E12, while Sox1 expression was observed only on E18. Sox6, 8, 9, and 12 showed expression at several stages. Although the expression of Sox $2,4,10,11$, and 21 was detected during all the four stages of tongue development, their expression patterns differed among the stages. We thus identified a dynamic spatiotemporal expression pattern of the Sox genes during murine tongue development. To understand whether Sox genes are involved in the development of other craniofacial organs through similar roles to those in tongue development, we also examined the expression of Sox genes in eyelid primordia, which also contain epithelium, mesenchyme, and muscle. However, expression patterns and timing of Sox genes differed between tongue and eyelid development. Sox genes are thus related to organogenesis through different functions in each craniofacial organ.
\end{abstract}

\section{Introduction}

The tongue plays a critical role in speaking, swallowing, mastication, and degustation. Malformations of the tongue, including macroglossia, hypoglossia, and aglossia, are seen as congenital defects. Therefore, it is crucial to understand the molecular mechanisms involved in tongue development; however, these mechanisms remain unclear.

The mammalian tongue is composed of the epithelium, connective tissue, and striated muscle. The connective tissue and vasculature of the tongue are derived from the cranial neural crest, whereas most tongue muscles are formed by myoblasts that migrate from the occipital somites [1]. It is believed that there is an interaction between neural crestderived and myogenic cells during tongue development $[2,3]$.

In mice, tongue development begins at embryonic day (E) 10.5-11.0 with the formation of medial lingual swelling from the first branchial arch. Next, lateral lingual swellings are formed on each side of the median tongue bud. They overgrow the medial lingual swelling and eventually fuse to form the anterior two-thirds of the tongue. The medial lingual swelling does not form any identifiable part of the adult tongue. The third branchial arch gives rise to the 
copula and the hypopharyngeal eminence. Subsequently, the hypopharyngeal eminence overgrows the copula, which in turn disappears progressively. Consequently, the rostral part of the hypopharyngeal eminence develops into the posterior third of the tongue $[2,3,4]$. Thus, the embryonic origin in the anterior two-thirds and posterior third of the tongue differs. In addition, the anterior twothirds of the tongue is mobile, whereas the posterior third is relatively immobile.

Tongue muscles are classified as either intrinsic or extrinsic. They are bilateral and separated by the lingual septum, which consists of fibrous connective tissue. Four different types of tongue papillae can be distinguished: fungiform, circumvallate, foliate, and filiform. They are known to develop through epithelial-mesenchymal interactions. Although the lingual epithelium is histologically homogeneous during the early stages of tongue development, the papillae become distinct and protrude from the dorsum of the tongue on approximately E12. A single circumvallate papilla is located at the center of the terminal sulcus. Fungiform papillae are present on the anterior part of the tongue in a pattern of longitudinal rows bracketing the median furrow. Unlike the other three types of papillae, filiform papillae cover the entire dorsal surface of the tongue.

Sox proteins are characterized by a highly conserved DNA-binding motif called high-mobility group domain. To date, 20 Sox genes have been identified in mice. Members of the Sox gene family show dynamic and diverse expression patterns during development, and they play multiple roles during development, as evidenced by mutation analyses in mice $[5,6]$. Spatiotemporal expression patterns of Sox genes have been reported in tooth and pancreas development $[7,8]$. In the trunk and limb region, it has been reported that Sox6 is involved in skeletal muscle formation, while Sox7, 15, 17 , and 18 have been shown to be related to function of satellite cells [9-13]. Although Sox2 has been reported to be involved in the development of tongue papillae [14], the expression pattern of other Sox genes during the entire development of the tongue remains unclear. Therefore, we performed a comparative in situ hybridization analysis of 17 Sox genes (Sox1-14, 17, 18, and 21) during murine tongue development and identified their dynamic spatiotemporal expression.

\section{Materials and Methods}

2.1. Production and Analysis of Mice. CD-1 strain mice were used in this study. The noon time of the day on which the plugs were detected was considered as E0.5. To accurately assess the age of the embryos, somite pairs were counted, and the stage was confirmed using morphological criteria, e.g., relative sizes of maxillary and mandibular primordia, extent of nasal placode invagination, and size of limb buds.

2.2. In Situ Hybridization. Embryo heads were fixed in $4 \%$ buffered paraformaldehyde, wax embedded, and serially sectioned at $7 \mu \mathrm{m}$. Decalcification using $0.5 \mathrm{M}$ EDTA (ethylenediaminetetraacetic acid, $\mathrm{pH}$ 7.6) was performed after fixation of the newborn mice. Sections were split over three to ten slides and prepared for histology or radioactive in situ hybridization. In situ hybridization with $\left[{ }^{35} \mathrm{~S}\right] \mathrm{UTP}$ labeled riboprobes (Table 1) was performed as previously described [15]. Briefly, the slides were pretreated with proteinase $\mathrm{K}$ and acetic anhydride to reduce the background. Hybridization was carried out overnight in a humidified chamber at $55^{\circ} \mathrm{C}$. The slides were then washed and treated with RNAse A for $30 \mathrm{~min}$ at $37^{\circ} \mathrm{C}$ to remove any nonspecifically bound probe. The high stringency washes were repeated, and the sections were then dehydrated. The slides were air-dried and dipped in Ilford K-5 photographic emulsion. Autoradiography was performed by exposing the sections in a light-tight box at $4^{\circ} \mathrm{C}$ for 10-14 days. Slides were developed using Kodak D19, fixed in Kodak Unifix, and counterstained with malachite green or hematoxylin.

\section{Results}

The expression of Sox 3 and 14 was not detected in the developing tongue (data not shown).

3.1. E11. The tongue primordium is firstly recognizable on the mandibular processes as a small protrusion (Figure 1(a)). To identify muscle progenitor cells, Myf5 expression was examined in the developing tongue. Two domains of $M y f 5$ expression were observed in the center of the tongue primordium, which was found to be further divided into four domains in the caudal region (Figure 1(b)). Sox4, 11, and 21 were ubiquitously expressed in the developing tongue (Figures 1(d), 1(f), and 1(g)). Sox 2 and 10 expressions were observed in the mesenchyme at the lateral side of the tongue primordium, whereas Sox 2 also showed the expression in the epithelium (Figures 1(c) and 1(e)). Sox1, 5, 6, 8, 9, and 12-14 showed no expression in the developing tongue at E11 (data not shown).

Since distinct morphological structures are present in the developing tongue along the anterior-posterior axis, it is likely that the expression patterns differ among the various regions of the developing tongue. Therefore, we examined the expression patterns of the Sox gene family members in the anterior, middle, and posterior regions of the tongue.

3.2. E12. At E12, condensation of mesenchymal cells was observed in the spatulate tongue (Figures 2(a)-2(a")). A primitive muscle was identified only in the middle and posterior regions of the developing tongue (Figures $2(a)-2\left(a^{\prime \prime}\right)$ ). Myf5 was expressed in primitive vertical and transverse (vt), genioglossus (gg), hyoglossus (hg), superior and inferior longitudinal (sil), geniohyoid (gh), and mylohyoid (mm) muscle regions (Figures $\left.2(\mathrm{~b})-2\left(b^{\prime \prime}\right)\right)$. Sox 2 was expressed in the mesenchyme between the sil and gg muscles in the middle and posterior regions of the tongue as well as in the epithelium throughout the tongue (Figures $\left.2(c)-2\left(c^{\prime \prime}\right)\right)$. The expression of 
TABle 1: Probe information.

\begin{tabular}{lcc}
\hline & Size of fragment of cDNA & Exon \\
\hline Sox1 & $255 \mathrm{bp}$ & 1 \\
Sox2 & $700 \mathrm{bp}$ & 1 \\
Sox3 & $900 \mathrm{bp}$ & 1 \\
Sox4 & $2.9 \mathrm{~kb}$ & 1 \\
Sox5 & $1.5 \mathrm{~kb}$ & $1-11$ \\
Sox6 & $5.0 \mathrm{~kb}$ & $2-16$ \\
Sox7 & $867 \mathrm{bp}$ & 2 \\
Sox8 & $780 \mathrm{bp}$ & $1-3$ \\
Sox9 & $510 \mathrm{bp}$ & 3 \\
Sox10 & $2.5 \mathrm{~kb}$ & $1-4$ \\
Sox11 & $3 \mathrm{~kb}$ & 1 \\
Sox12 & $900 \mathrm{bp}$ & 1 \\
Sox13 & $3.3 \mathrm{~kb}$ & $2-11$ \\
Sox14 & $1.9 \mathrm{~kb}$ & 1 \\
Sox17 & $960 \mathrm{bp}$ & 4,5 \\
Sox18 & $856 \mathrm{bp}$ & 2 \\
Sox21 & $714 \mathrm{bp}$ & 1 \\
\hline
\end{tabular}

Sox4 was found in the septum of the posterior region of the tongue (Figures $\left.2(\mathrm{~d})-2\left(\mathrm{~d}^{\prime \prime}\right)\right)$. Sox 5 was weakly expressed in the mesenchyme between the sil and gg muscles in the middle and posterior regions of the tongue (Figures $2(\mathrm{e})-2\left(\mathrm{e}^{\prime \prime}\right)$ ). Weak expression of Sox 6 was observed in the epithelium and vt and gg muscles (Figures 2(f)-2(f $\left.\mathrm{f}^{\prime \prime}\right)$ ). Sox9 expression was observed in vt muscles, mesenchyme between vt muscles, and epithelium of the entire tongue (Figures $2(\mathrm{~g})-2\left(\mathrm{~g}^{\prime \prime}\right)$ ). Sox10 expression was detected in the mesenchyme between the sil and gg muscles in the middle and posterior regions of the tongue as well as in the hg muscle region (Figures $2(\mathrm{~h})-2\left(\mathrm{~h}^{\prime \prime}\right)$ ). Sox11 was ubiquitously expressed in the developing tongue (Figures $2(\mathrm{i})-2\left(\mathrm{i}^{\prime \prime}\right)$ ). Weak expression of Sox13 was observed in the mesenchyme between the sil and gg muscles in the middle and posterior regions of the tongue (Figures $\left.2(j)-2\left(j^{\prime \prime}\right)\right)$. Sox 21 was expressed in the lingual septum of the posterior developing tongue (Figures $2(\mathrm{k})-2\left(\mathrm{k}^{\prime \prime \prime}\right)$ ). Soxl, 8 , and 12 showed no expression in the developing tongue at E12 (data not shown). Sox5, 6, and 9 also showed strong expressions in the presumptive Meckel's cartilage region.

3.3. E13. The vt, gg, and hg muscles were histologically identifiable at E13 (Figures 3(a)-3( $\left.a^{\prime \prime}\right)$ ). Myf5 expression in the anterior and middle regions of the tongue was comparable to that at E12, while it was divided into two expression domains in the gg muscles (Figures $3(\mathrm{~b})-3\left(\mathrm{~b}^{\prime \prime}\right)$ ). Sox2 was expressed in the mesenchyme between the vt and sil muscles and epithelium of the entire tongue (Figures 3(c)-3( $\left(c^{\prime \prime}\right)$ ). The expression of Sox4 was observed in the mesenchyme surrounding the vt muscles, including the lingual septum throughout the tongue (Figures $3(\mathrm{~d})-3\left(\mathrm{~d}^{\prime \prime}\right)$ ). Sox6 was expressed in the epithelium and the vt, gg, hg, and sil muscles of the entire developing tongue (Figures $3(e)-3\left(e^{\prime \prime}\right)$ ). Sox 8 was weakly expressed in the septum of the entire tongue, the sil muscle in the anterior and middle tongue, and the gg muscle in the posterior regions of the tongue (Figures $\left.3(\mathrm{f})-3\left(\mathrm{f}^{\prime \prime}\right)\right)$. Expression of Sox9 was detected in the lingual septum in the entire tongue, while it was also weakly expressed in the sil muscle of the entire tongue (Figures $3(\mathrm{~g})-3\left(\mathrm{~g}^{\prime}\right)$. Weak expression of Sox9 was also found in the gg muscle region of the posterior tongue (Figures $3\left(\mathrm{~g}^{\prime \prime}\right)$ ). Sox10 was expressed in the mesenchyme between the vt and sil muscles in the entire tongue, as well as in the gg muscle in the posterior region of the tongue (Figures $3(\mathrm{~h})-3\left(\mathrm{~h}^{\prime \prime}\right)$ ). Sox11 showed ubiquitous expression in the entire developing tongue (Figures $\left.3(\mathrm{i})-3\left(\mathrm{i}^{\prime \prime}\right)\right)$. Sox12 was expressed in the epithelium of the entire tongue, and the vt and gg muscles in the posterior region of the tongue (Figures $\left.3(j)-3\left(j^{\prime \prime}\right)\right)$. Sox21 expression was observed in the vt muscle in the anterior and middle tongue, while it was found in the septum in the middle and posterior tongue (Figures $3(\mathrm{k})-3\left(\mathrm{k}^{\prime \prime \prime}\right)$ ). Sox 1,5 , and 13 showed no expression in the developing tongue at E13 (data not shown).

3.4. E14. Each muscle was found to be more morphologically obvious at E14 (Figures $4(\mathrm{a})-4\left(\mathrm{~b}^{\prime \prime}\right)$ ). Myf5 was also expressed in the gg muscle in the anterior tongue (Figures 4(b)). Myf5 expression was divided into several domains in the vt muscle region of the entire developing tongue (Figures $4(\mathrm{~b})$ and $4\left(\mathrm{~b}^{\prime}\right)$ ). Sox2 showed expression in the epithelium of the entire tongue (Figures $4(c)-4\left(c^{\prime \prime}\right)$ ). Expression of Sox 4 was observed in the mesenchyme surrounding the vt muscles, including the septum throughout the tongue, as well as in the epithelium (Figures $4(\mathrm{~d})-4\left(\mathrm{~d}^{\prime \prime}\right)$ ). Sox6 showed expression in the vt, hg, and gg muscles in the entire tongue, as well as in the epithelium (Figures $4(e)-4\left(e^{\prime \prime}\right)$ ). Sox 8 showed weak and ubiquitous expression in the entire tongue (Figures $4(\mathrm{f})-4\left(\mathrm{f}^{\prime \prime}\right)$ ). In the anterior and middle regions of the tongue, Sox9 was strongly expressed in the gg muscles, and weakly expressed in the sil muscle (Figures $\left.4(\mathrm{~g})-4\left(\mathrm{~g}^{\prime \prime}\right)\right)$. Expression of Sox10 was observed in the mesenchyme underneath the vt muscles in the anterior and middle regions of the tongue, and in the gg muscle in the posterior region (Figures $4(\mathrm{~h})-4\left(\mathrm{~h}^{\prime \prime}\right)$ ). Weak expression of Sox 11 was detected in the epithelium of the entire tongue and gg muscles in the anterior region of the tongue (Figures $4(\mathrm{i})-4\left(\mathrm{i}^{\prime \prime}\right)$ ). Sox12 showed weak expression in the epithelium of the entire tongue and the gg muscles in the posterior part of the tongue (Figures $\left.4(j)-4\left(j^{\prime \prime}\right)\right)$. Sox21 showed ubiquitous expression in the entire developing tongue (Figures $\left.4(\mathrm{k})-4\left(\mathrm{k}^{\prime \prime}\right)\right)$. Soxl, 5, and 13 showed no expression in the developing tongue at E14 (data not shown).

3.5. E18. Most tongue muscle progenitor cells had already been differentiated into myoblasts by E18. Therefore, only weak expression of Myf5 could be observed in the tongue at E18 (data not shown). Sox1 showed weak expression in the sil, vt, gg, and gh muscles in the middle and posterior regions of the tongue (Figures $5(b)-5\left(b^{\prime \prime}\right)$ ). Sox 2 has been shown to be expressed in the epithelium at this developmental stage [14]. Sox4 showed weak expression in the epithelium and vt muscles in the middle and posterior regions of the tongue (Figures 5(c)-5( $\left.c^{\prime \prime}\right)$ ). Sox6 showed ubiquitous expression in the entire tongue (Figures $5(\mathrm{~d})-5\left(\mathrm{~d}^{\prime \prime}\right)$ ). Expression of Sox8 was 

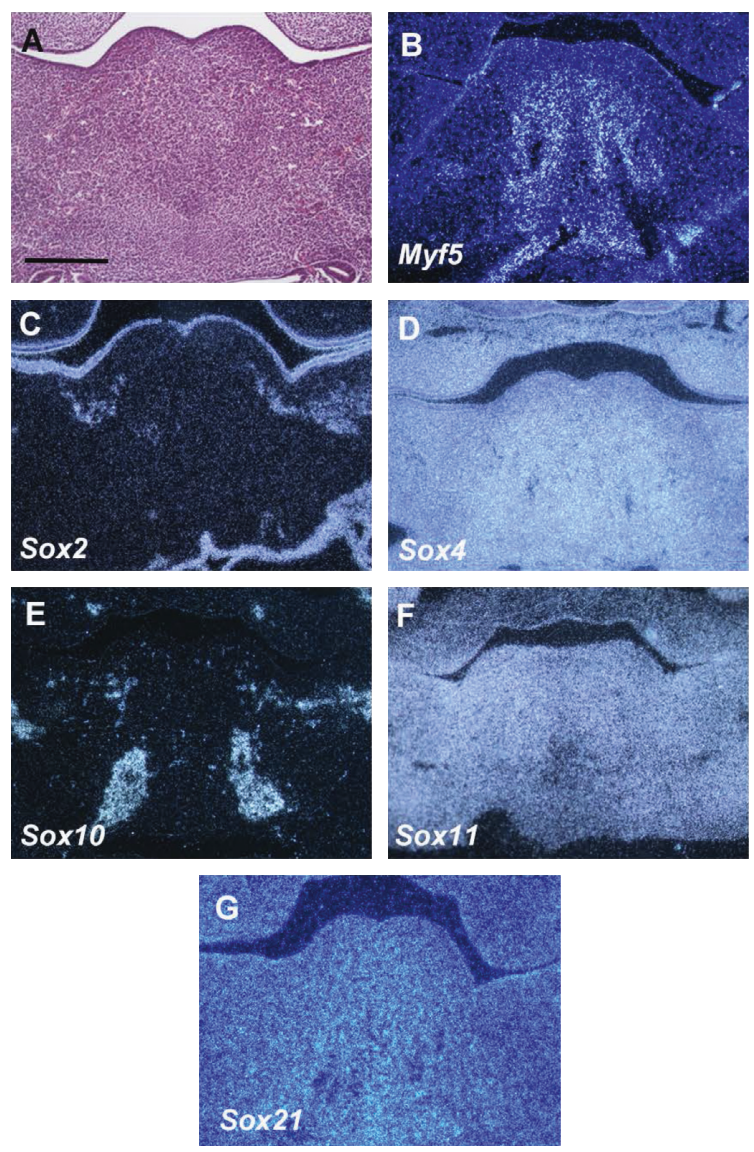

Figure 1: Expression of Sox genes in tongue development at E11. Frontal sections showing histology (a) and in situ hybridization (b-g) in wild-type tongue at E11. Scale bar: $300 \mu \mathrm{m}$ for (a-g).

detected in the mesial part of the vt muscles in the anterior region of the tongue, as well as in both the mesial part of the vt muscles and the rostral part of the gg muscle in the posterior region of the tongue (Figures $\left.5(\mathrm{e})-5\left(\mathrm{e}^{\prime \prime}\right)\right)$. Weak expression of Sox10 was found in the vt muscles in the middle and posterior regions of the tongue, as well as in the epithelium in the posterior region of the tongue (Figures $5(\mathrm{f})-5\left(\mathrm{f}^{\prime \prime}\right)$ ). Sox 11 was weakly expressed in the dorsum epithelium in the anterior region of the tongue (Figures $5(\mathrm{~g})-5\left(\mathrm{~g}^{\prime \prime}\right)$ ). Sox 12 expression was detected in the vt muscles in the middle region of the tongue, as well as in the vt and sil muscles in the posterior region of the tongue (Figures $5(\mathrm{~h})-5\left(\mathrm{~h}^{\prime \prime}\right)$ ). Sox21 showed ubiquitous expression in the entire developing tongue (Figures 5(i)-5(i")). Sox2, 5, 9, and 13 showed no expression in the developing tongue at E18 (data not shown).

Sox7, 17, and 18 belong to group F of the Sox gene family (SoxF). Members of SoxF have been shown to regulate blood and lymphatic vascular development [16-18]. A punctate expression pattern of Sox7, 17, and 18 was seen throughout the developing tongue, and it probably represents vascularization of the tissue (data not shown).
3.6. Sox Genes in Eyelid Development. Among the craniofacial organs, the eyelid shows some similarities with the tongue: Both are mobile organs and develop through epithelium, neural crest-derived mesenchyme, and mesoderm $[2,3,19,20]$. In addition, it has been shown that the lack of Shh signaling pathway and microRNAs result in developmental defects of both the eyelid and the tongue [21-25]. These features suggest the possibility that tongue and eyelid development are under similar molecular mechanisms. To understand whether Sox genes are also involved in other craniofacial organs through similar roles as those in tongue development, we examined the expression of Sox genes in eyelid development. Murine eyelid initiates by groove formation at approximately E11, and the protrusion of the eyelid primordia occurs from E12 (Figures 6(a), 6(f), 6(k), and $6(\mathrm{p}))[20]$. Fusion of eyelid is observed at approximately E16, since the mammalian eyes require temporary fusion and re-opening between the upper and lower eyelids during their development and growth (Figure 6(u)). Myf5 expression was observed in the eyelid primordia only at E14 and E18 (Figures $6\left(\mathrm{a}^{\prime}\right), 6\left(\mathrm{f}^{\prime}\right), 6\left(\mathrm{k}^{\prime}\right), 6\left(\mathrm{p}^{\prime}\right)$, and $6\left(\mathrm{u}^{\prime}\right)$ ). At E11, Sox4, 11, and 21 showed ubiquitous expressions in the developing eyelid, whereas Sox6 was only expressed in 

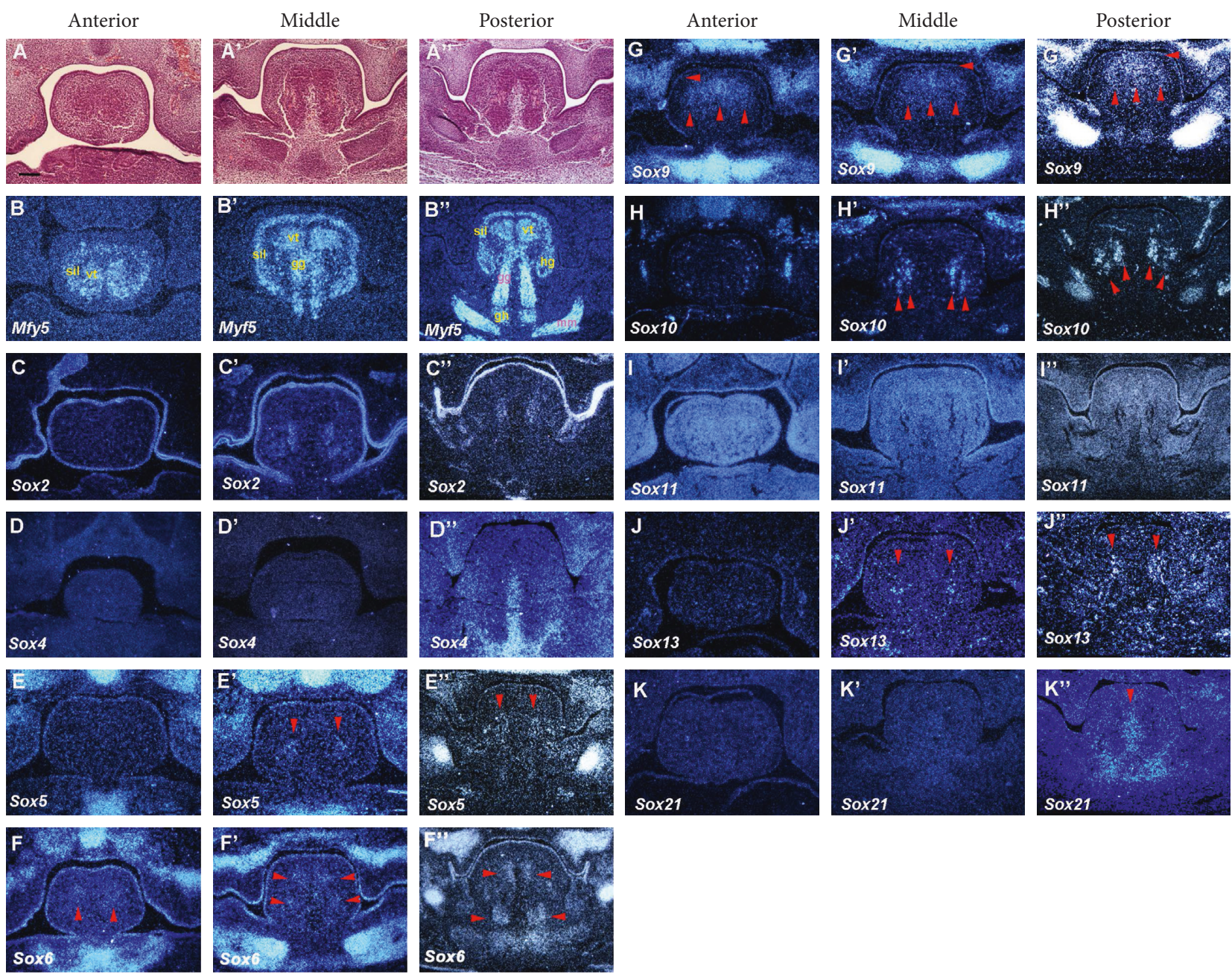

Figure 2: Expression of Sox genes in tongue development at E12. Frontal sections showing histology ((a)-(a")) and in situ hybridization $\left((\mathrm{b})-\left(\mathrm{k}^{\prime \prime}\right)\right)$ at the anterior, middle, and posterior regions of mandible in wild-type at E12. Vertical and transverse muscle (vt), genioglossus muscle (gg), superior and inferior longitudinal muscle (sil), geniohyoid muscle (gh), mylohyoid (mm), and hyoglossus muscle (hg). Arrowheads indicate weak expression. Scale bar: $125 \mu \mathrm{m}$ for $(\mathrm{a})-\left(\mathrm{k}^{\prime \prime}\right)$.

the eyelid epithelium (Figures 6(b)-6(e)). At E12 and E13, Sox4 and 11 expressions were observed in both the epithelium and mesenchyme, whereas Sox6 and 9 were only expressed in the epithelium (Figures 6(g)-6(j) and 6(l)-6(o)). At E14, Sox4 was ubiquitously expressed in the developing eyelid, with a slightly stronger expression in the muscles (Figure 6(q)). Sox6, 9, and 12 were expressed in the epithelium of eyelid primordia, whereas Sox11 expression was observed in both the epithelium and mesenchyme (Figures $6(\mathrm{r})-6(\mathrm{t})$ ), data not shown). At E18, Sox21 was ubiquitously expressed in the developing eyelid, with a slightly stronger expression in the muscles (Figure 6(y)). Expressions of Sox4 and 6 could be observed in the muscle of eyelid primordia, whereas Sox11 was expressed in the epithelium (Figures 6(v)-6(x)). Sox4, 6, and 11 were also expressed in the extraocular muscle region. Expressions of Sox1-3, 5, 8, 10,13 , and 14 could not be detected in the developing eyelid (data not shown).

\section{Discussion}

The mammalian tongue is composed of the epithelium, connective tissue, and striated muscle. Our comparative in situ hybridization analysis demonstrated a dynamic spatiotemporal expression pattern of Sox genes during murine tongue development. Sox 2 and 11 were expressed in the tongue epithelium during all five stages investigated in this study, whereas Sox 8 and 9 were expressed in the tongue epithelium only at E14 and E12, respectively. Sox4, 6, 12, and 21 showed expressions in the epithelium at several stages (Table 2). Sox4 and 21 were expressed in the mesenchyme at all stages, whereas Sox5, 6, and 13 were only detected in the mesenchyme at E12 (Sox5, 13) and E18 (Sox6). Sox2, 8, 9, 10, and 11 showed detectable expressions in the mesenchyme at several stages (Table 2). Unlike the epithelium and mesenchyme, none of the Sox genes were expressed in the tongue muscle during all five stages. Sox 1 was expressed in 

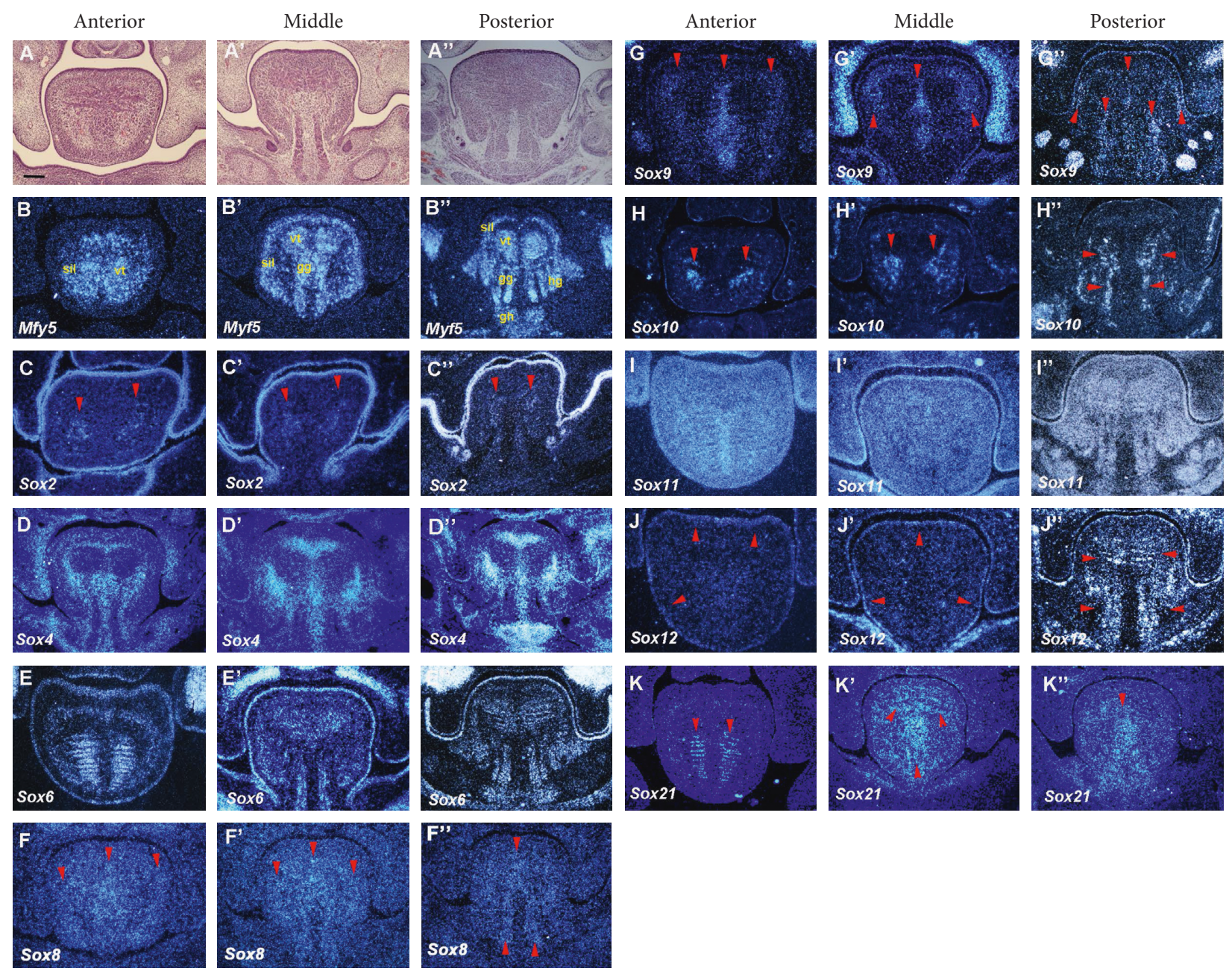

FIgURE 3: Expression of Sox genes in tongue development at E13. Frontal sections showing histology ((a)-(a")) and in situ hybridization $\left((b)-\left(k^{\prime \prime}\right)\right)$ at the anterior, middle and posterior regions of mandible in wild-type at E13. Vertical and transverse muscle (vt), genioglossus muscle (gg), superior and inferior longitudinal muscle (sil), geniohyoid muscle (gh), hyoglossus muscle (hg). Arrowheads indicate weak expression. Scale bar: $125 \mu \mathrm{m}$ for (a)-( $\left.\mathrm{k}^{\prime \prime}\right)$.

the tongue muscle only at E18. Sox 6 and 10 were not detected in the muscle at E11 but were expressed during the other four developmental stages (E12-E18). Additionally, Sox11 was not expressed in the muscle at E18 but was expressed during the other four developmental stages (E11-E14). Sox4, 8, 9, 12, and 21 showed detectable expressions in the muscle at several stages (Table 2). Sox1 was only expressed in the muscle, whereas Sox 5 and 13 were expressed only in the mesenchyme. Sox 2 could not be detected in the muscle at any stage, whereas Sox 12 showed no expression in the mesenchyme at any stage. Although the expressions of Sox2, 4, 10,11, and 21 were detected in the developing tongue during all five stages investigated in this study, their expression patterns differed among the stages. Our results also revealed a different expression pattern of Sox genes between the anterior, middle, and posterior region of the developing tongue (Figure 7). Sox genes thus showed a dynamic spatiotemporal expression pattern during murine tongue development.

Fungiform, circumvallate, and foliate papillae contain taste buds and are referred to as taste (or gustatory) papillae, whereas filiform papillae do not contain taste buds and are thus regarded nongustatory. Although Sox 2 has been shown to play a critical role in regulating the formation of gustatory papillae, its expression has also been detected in the nongustatory tongue epithelium [14]. Our results revealed that Sox $2,4,6,8,9,10,11,12$, and 21 were expressed in the epithelium of the entire tongue. Although none of these genes showed a restricted expression pattern in the tongue papillae, it is possible that they are involved in regulating the formation of all papillae types.

Skeletal muscle fibers are classified as "slow-twitch fiber" (type I) and "fast-twitch fiber" (type II), which display marked differences in contraction strength, metabolic strategies, and susceptibility to fatigue. Slow-twitch fibers are rich in mitochondria, have increased contraction endurance with lesser strength potential, and use predominantly oxidative phosphorylation for energy production. Fast-twitch fibers contain comparatively less numbers of mitochondria and rely more heavily on anaerobic glycolysis for energy production, which allows considerable strength and contraction speed, but only for short anaerobic bursts of activity 


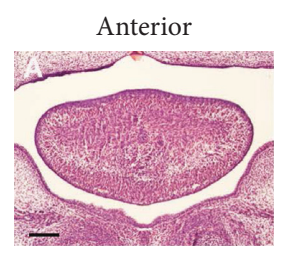

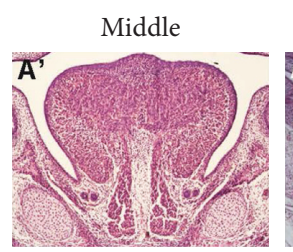

Posterior
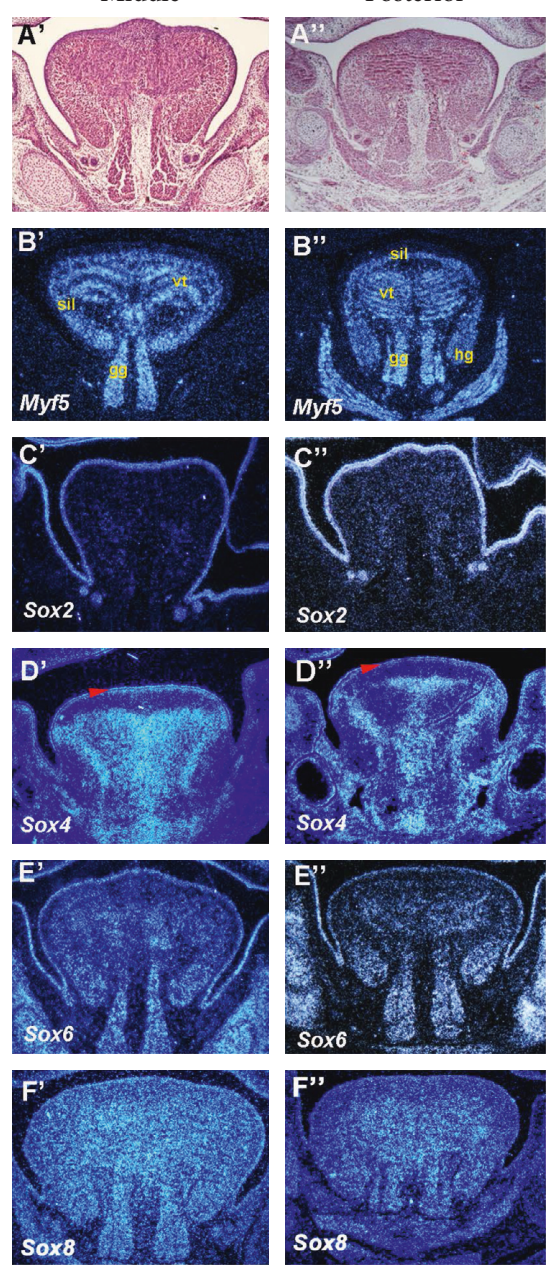
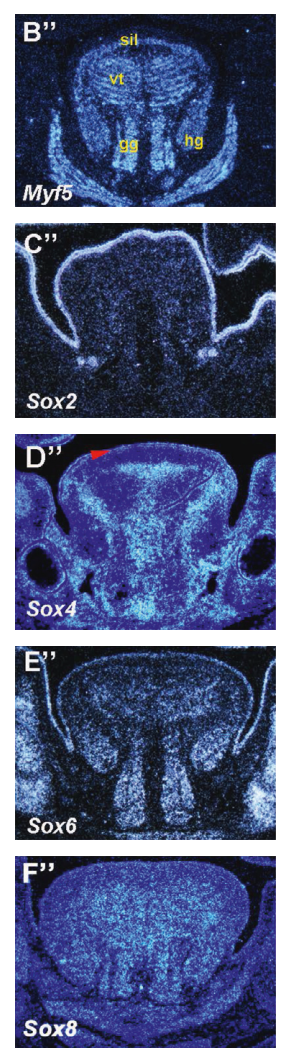

Anterior
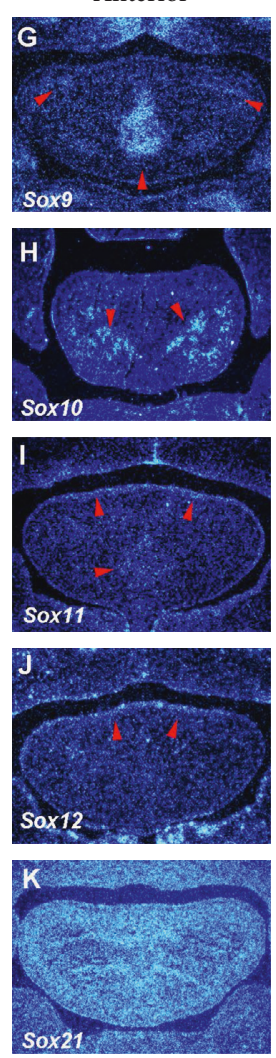

Middle
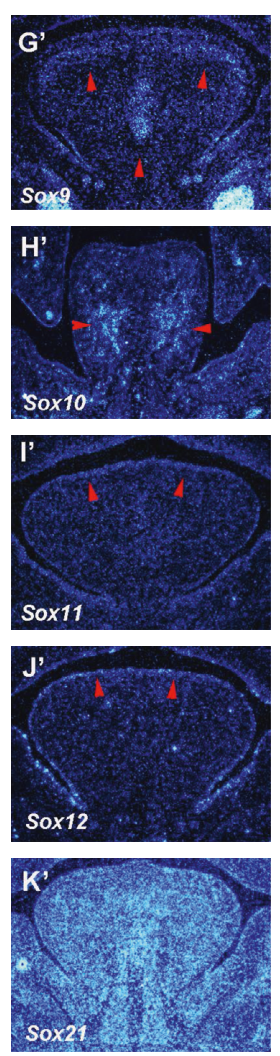

Posterior
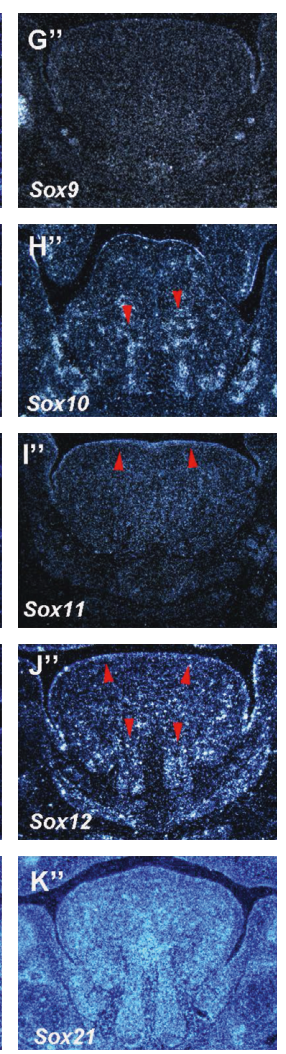

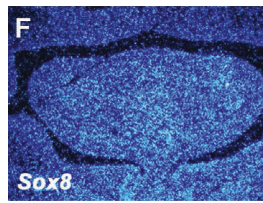

Figure 4: Expression of Sox genes in tongue development at E14. Frontal sections showing histology ((a)-(a")) and in situ hybridization $\left((b)-\left(k^{\prime \prime}\right)\right)$ at the anterior, middle and posterior regions of mandible in wild-type at E14. Vertical and transverse muscle (vt), genioglossus muscle (gg), superior and inferior longitudinal muscle (sil), geniohyoid muscle (gh), hyoglossus muscle (hg). Arrowheads indicate weak expression. Scale bar: $300 \mu \mathrm{m}$ for $(\mathrm{a})-\left(\mathrm{k}^{\prime \prime}\right)$.

before the muscles fatigue. It has been reported that Sox6 is involved in fast-twitch muscle fiber differentiation in the trunk region $[9,10]$. It is known that rodent tongue is composed of only fast-twitch fiber, and we also found Sox6 expression in the muscles of the developing tongue [26, 27]. These suggest that Sox6 is likely to be involved in fast-twitch muscle fiber differentiation during tongue development. Sox 8, 9, 10, 12, and 21 were observed in the tongue muscles where Sox6 was expressed, suggesting the possibility that these Sox genes also regulate fast-twitch muscle fiber differentiation. On the other hand, unlike the mouse tongue, the human tongue shows high proportion of slow-twitch fibers, suggesting that the role of Sox genes differs between the human and mouse tongue [28].

The developmental origin of the masticatory muscles is the cardiopharyngeal mesoderm, while the tongue and other muscles, including the trunk and limb muscles, are derived from the somites [29]. Although the embryonic origins are the same in the tongue, limb, and trunk muscle, it has been shown that the program controlling tongue myogenesis, including the specification and migration of muscle progenitor cells, differs from those of the trunk and limb myogenesis $[2,3,30]$. Therefore, we could not exclude the possibility that the role of Sox genes expressing in developing tongue muscle differ from that in trunk and limb muscle development.

The tongue consists of many types of muscles, including vt, sil, and gg muscles [2, 30, 31]. Although our results indicated that many Sox genes were expressed in these tongue muscles, there was no specific Sox gene expressing in the particular muscles (Figure 7). Sox genes are therefore unlikely to play a critical role in tongue muscle specification. Different expression patterns between Sox genes in each tongue muscle type suggested that each muscle type is controlled by different molecular mechanisms during development.

Skeletal myogenesis consists of six phases: specification, migration, proliferation, determination, differentiation, and 
Anterior

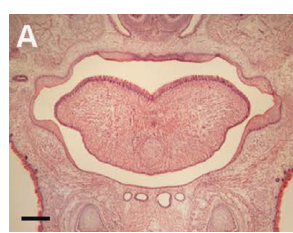

B

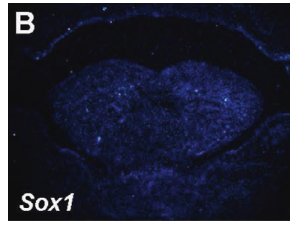

C
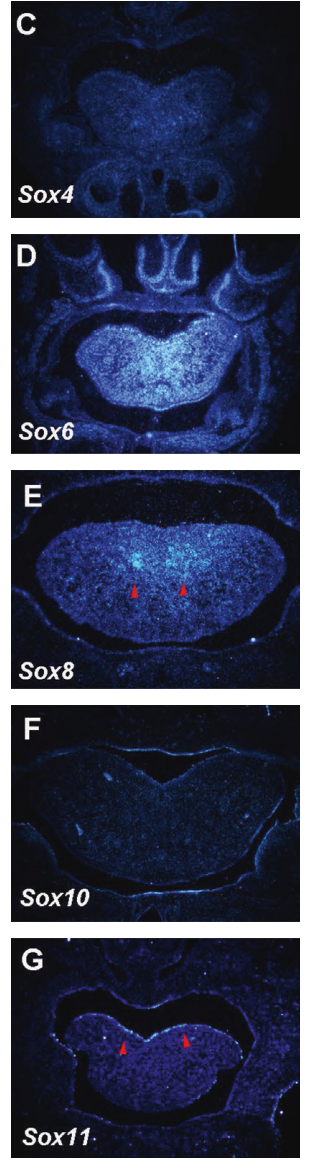

H

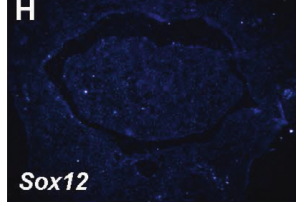

$I^{2}$

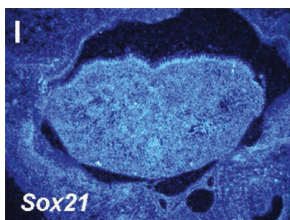

Middle
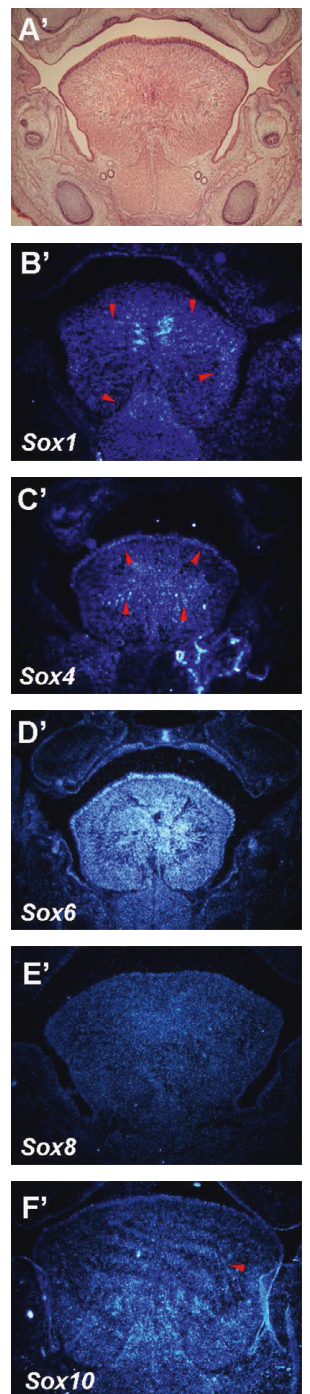

'

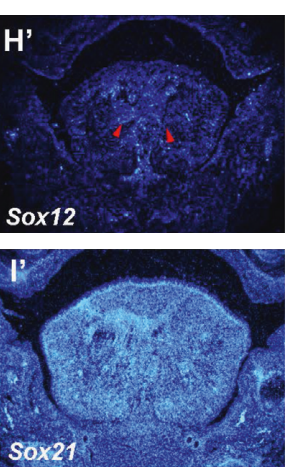

Posterior
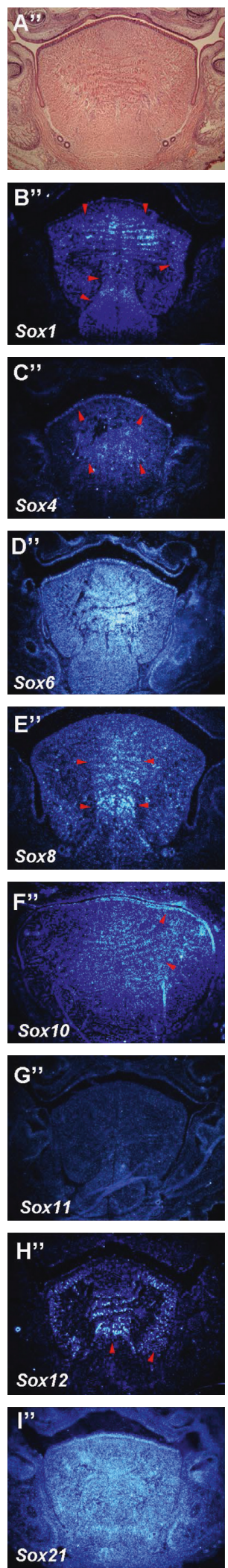

Figure 5: Expression of Sox genes in tongue development at E18. Frontal sections showing histology ((a)-(a")) and in situ hybridization $\left((b)-\left(i^{\prime \prime}\right)\right)$ at the anterior, middle, and posterior regions of mandible in wild-type at E18. Arrowheads indicate weak expression. Scale bar: $700 \mu \mathrm{m}$ for $(\mathrm{a})-\left(\mathrm{i}^{\prime \prime}\right)$. 

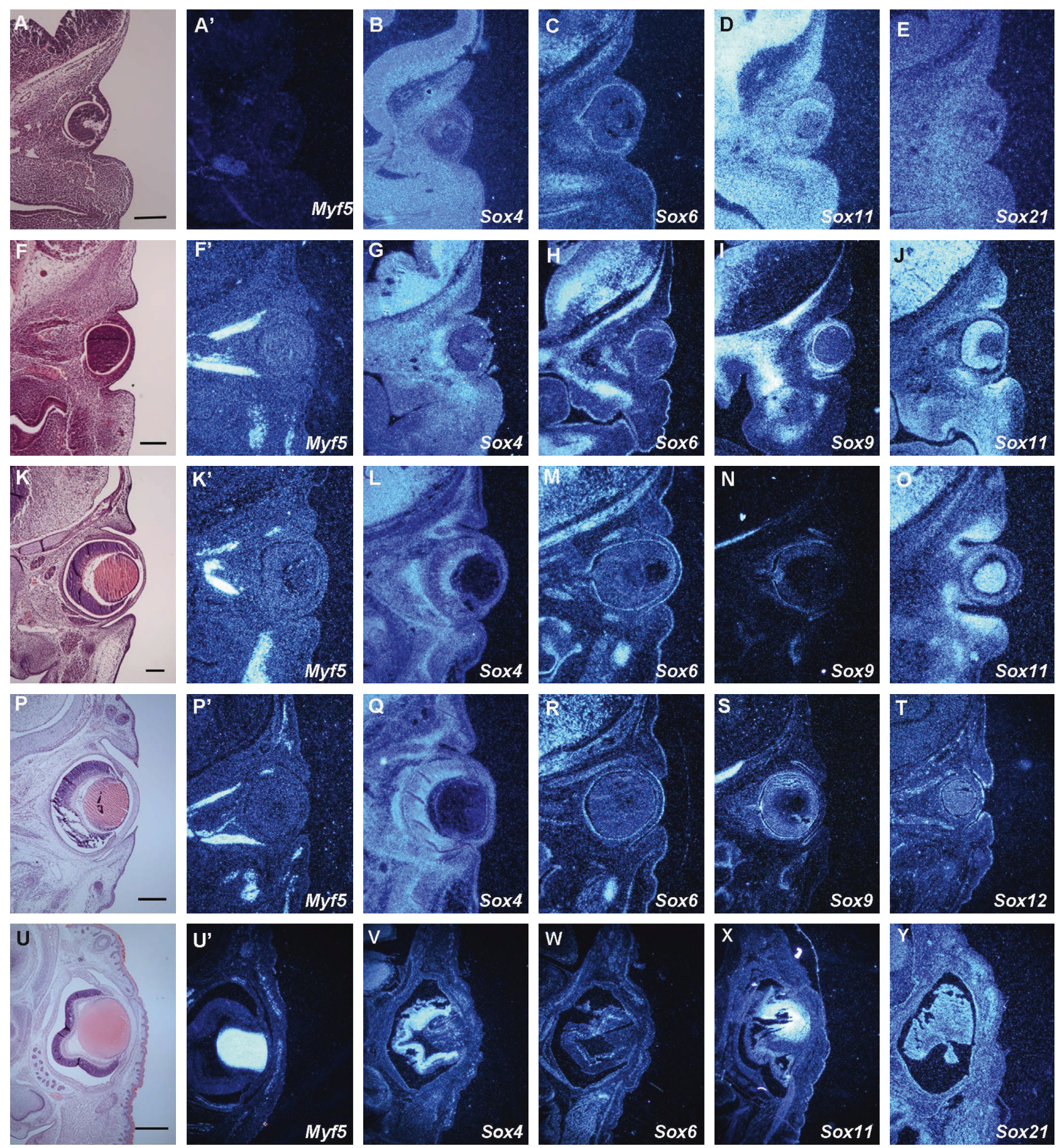

Figure 6: Expression of Sox genes in eyelid development. Frontal sections showing histology (a), (f), (k), (p), (u) and in situ hybridization $\left(\left(\mathrm{a}^{\prime}\right)-(\mathrm{e}),\left(\mathrm{f}^{\prime}\right)-(\mathrm{j}),\left(\mathrm{k}^{\prime}\right)-(\mathrm{o}),\left(\mathrm{p}^{\prime}\right)-(\mathrm{t})\right.$, and $\left.\left(\mathrm{u}^{\prime}\right)-(\mathrm{y})\right)$ in wild type at E11 ((a)-(e)), E12 ((f)-(j)), E13 ((k)-(o)), E14 ((p)-(t)), and E18 ((u)-(y)). Scale bar: $150 \mu \mathrm{m}$ for (a)-(e), $125 \mu \mathrm{m}$ for (f)-(j), $125 \mu \mathrm{m}$ for (k)-(o), $300 \mu \mathrm{m}$ for (p)-(t), $700 \mu \mathrm{m}$ for (u)-(y).

maturation $[1,2,29-31]$. It is unlikely that each phase of myogenesis proceeds at the same time in all types of tongue muscle since the timing of appearance differs between muscle types in the tongue $[1,2,29-32]$. It is possible that the different expression patterns of Sox genes in tongue muscles could be correlated with the onset of these stages, although the molecular mechanisms regulating the initiation of each phase during tongue development remain unclear. It has been shown that Sox7, 15, 17 and 18 are involved in the function of satellite cells after birth, although these are not exerted at embryonic stages [11-13]. Therefore, a punctate expression pattern of Sox7, 17, and 18 observed in the embryonic tongue are likely to represent vascularization of the tissue. Furthermore, these also indicated that function of 
TABLE 2: Summary of expression of Sox genes in developing tongue and eyelid.

\begin{tabular}{|c|c|c|c|c|c|c|c|c|c|c|c|c|}
\hline \multicolumn{13}{|c|}{ Tongue epithelium } \\
\hline E11 & - & Sox 2 & Sox $4^{*}$ & - & - & - & - & - & Sox $11^{*}$ & - & - & Sox $21^{*}$ \\
\hline E12 & - & Sox 2 & - & - & Sox6 & - & Sox9 & - & Sox $11^{*}$ & - & - & - \\
\hline E13 & - & Sox 2 & - & - & Sox6 & - & - & - & Sox $11^{*}$ & Sox 12 & - & - \\
\hline E14 & - & Sox 2 & Sox4 & - & Sox6 & So $\times 8^{*}$ & - & - & Sox11 & So $\times 12$ & - & So $21^{*}$ \\
\hline E18 & - & Sox 2 & Sox 4 & - & Sox $6^{*}$ & - & - & So $\times 10$ & Sox 11 & - & - & So $21^{*}$ \\
\hline \multicolumn{13}{|c|}{ Tongue mesenchyme } \\
\hline E11 & - & Sox 2 & Sox $4^{*}$ & - & - & - & - & Sox10 & Sox $11^{*}$ & - & - & Sox $21^{*}$ \\
\hline E12 & - & Sox 2 & Sox 4 & Sox 5 & - & - & Sox9 & Sox10 & Sox $11^{*}$ & - & Sox 13 & Sox 21 \\
\hline E13 & - & Sox 2 & Sox 4 & - & - & Sox8 & Sox9 & Sox10 & Sox $11^{*}$ & - & - & Sox 21 \\
\hline E14 & - & - & Sox 4 & - & - & So $\times 8^{*}$ & - & Sox10 & - & - & - & So $21^{*}$ \\
\hline E18 & - & - & Sox 4 & - & Sox6* & - & - & - & - & - & - & So $21^{*}$ \\
\hline \multicolumn{13}{|c|}{ Tongue muscle } \\
\hline E11 & - & - & So $\times 4^{*}$ & - & - & - & - & - & Sox $11^{*}$ & - & - & So $21^{*}$ \\
\hline E12 & - & - & - & - & Sox6 & - & Sox9 & Sox10 & Sox $11^{*}$ & - & - & - \\
\hline E13 & - & - & - & - & Sox6 & Sox8 & Sox9 & So $\times 10$ & Sox $11^{*}$ & So $\times 12$ & - & So 21 \\
\hline E14 & - & - & - & - & Sox6 & So $\times 8^{*}$ & Sox9 & Sox10 & Sox11 & Sox 12 & - & So $21^{*}$ \\
\hline E18 & So 1 & - & Sox 4 & - & Sox6* & Sox8 & - & So $\times 10$ & - & So $\times 12$ & - & So $21^{*}$ \\
\hline \multicolumn{13}{|c|}{ Eyelid mesenchyme } \\
\hline E11 & - & - & So $x 4^{*}$ & - & - & - & - & - & Sox $11^{*}$ & - & - & So $\times 21^{*}$ \\
\hline E12 & - & - & Sox 4 & - & - & - & - & - & Sox11 & - & - & - \\
\hline E13 & - & - & Sox 4 & - & - & - & - & - & Sox 11 & - & - & - \\
\hline E14 & - & - & Sox $4^{*}$ & - & - & - & - & - & Sox11 & - & - & - \\
\hline E18 & - & - & - & - & - & - & - & - & - & - & - & So $21^{*}$ \\
\hline \multicolumn{13}{|c|}{ Eyelid muscle } \\
\hline E14 & - & - & Sox $4^{*}$ & - & - & - & - & - & - & - & - & - \\
\hline E18 & - & - & Sox4 & - & Sox6 & - & - & - & - & - & 一 & So 21 \\
\hline
\end{tabular}

*Ubiquitous expression.

Sox genes differ between embryonic and postnatal stages in tongue formation.

Previous studies have reported that neural crestderived cells give rise to tissues surrounding the skeletal muscles, including the perimysium, epimysium, endomysium, and tendon, during tongue development $[33,34]$. Sox genes have been shown to regulate the functions of neural crest-derived cells including their differentiation, collagen synthesis, and melanocyte formation [35, 36, 37]. In our study, Sox 9 displayed a restricted expression pattern in the lingual septum, which is composed of neural crestderived cells $[2,3]$. It has been reported that Scleraxis is expressed in a similar pattern to that of Sox9 during tongue development [2, 32]. Interestingly, Sox9 shows coordinated expression with Scleraxis during digital tendon development [38]. Therefore, it is possible that Sox9/Scleraxisexpressing cells are involved in the formation of tongue muscle tendons.

The origin of the tongue is known to be hybrid, neural crest-derived cells, the mesoderm, and endoderm. It has been shown that there is an interaction between neural crestderived and myogenic cells during tongue development $[2,3]$. We detected the expressions of Sox 1, 4, 6, 8, 9, 10, 11, 12,13 , and 21 in the muscles of the developing tongue and of Sox 2, 4, 5, 6, 8, 9, 10, 11, and 21 in the mesenchyme. It is possible that these genes are involved in the interaction between neural crest-derived and myogenic cells during tongue development. In fact, some Sox genes have been proven to be involved in the interaction between the epithelium and mesenchyme in digestive tract development $[39,40]$.

Members of the Sox gene family play multiple roles during development $[5,6]$. The dynamic spatiotemporal expression pattern of Sox genes discovered in this study indicates their critical role during murine tongue development. We also examined the expression of Sox genes in eyelid development (Table 2). Both organs consist of connective tissue, muscle, and epithelium, and there is an interaction between these tissues during their development $[2,3,19,20]$. In addition, both tongue and eyelid are mobile organs. Although there are thus numerous similarities between the eyelid and tongue, our results showed that the expression patterns and timing of Sox genes significantly differed between tongue and eyelid development. Sox genes are thus likely to be involved in organogenesis through different functions in each organ.

\section{Conclusion}

Sox genes show a dynamic spatiotemporal expression pattern during murine tongue development. 

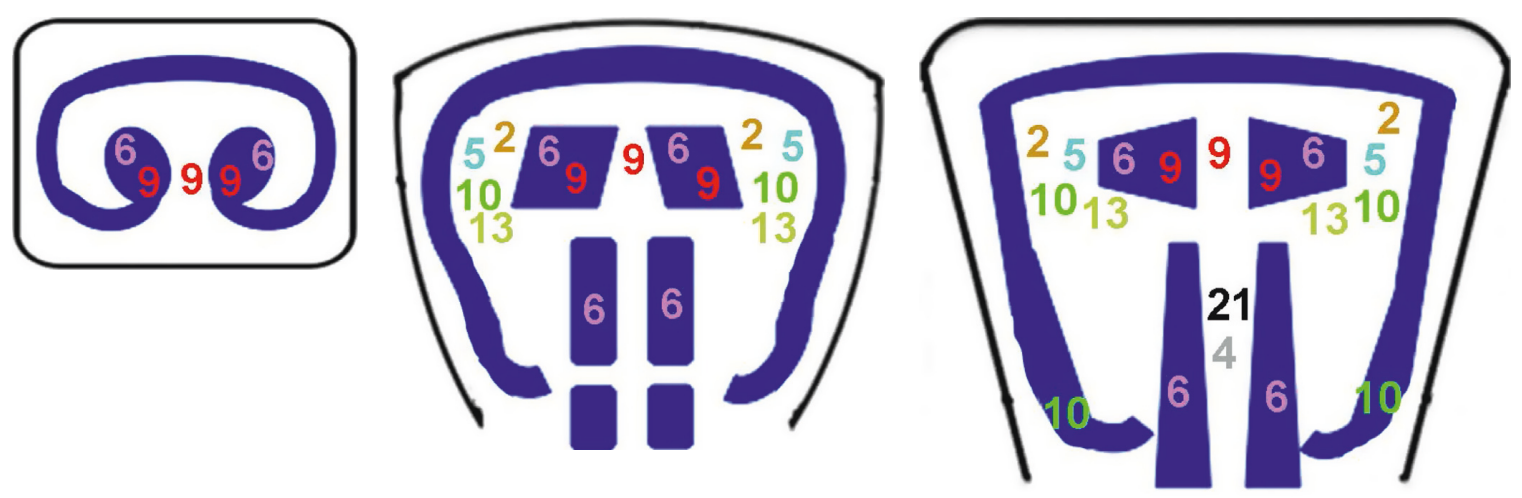

(a)
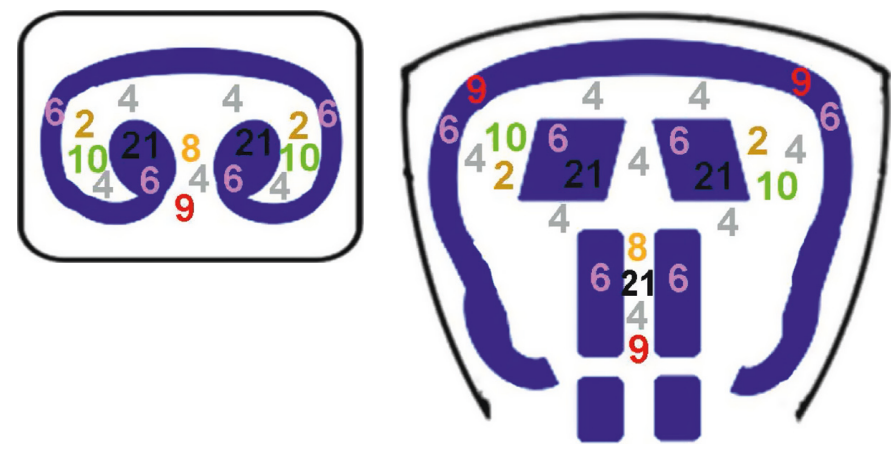

(b)

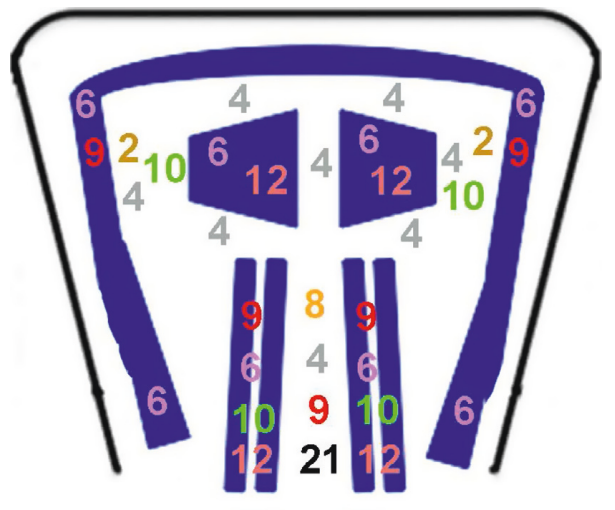

(e)

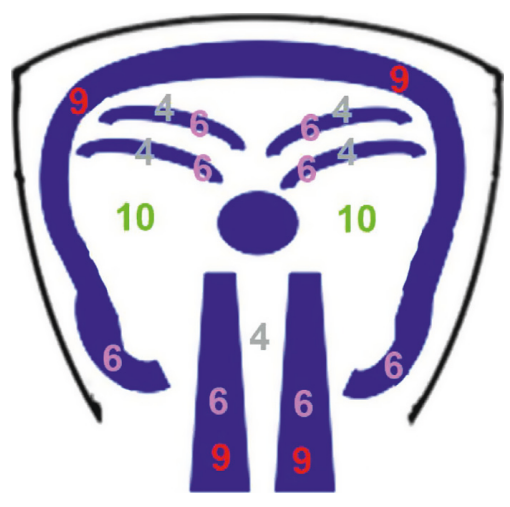

(h)

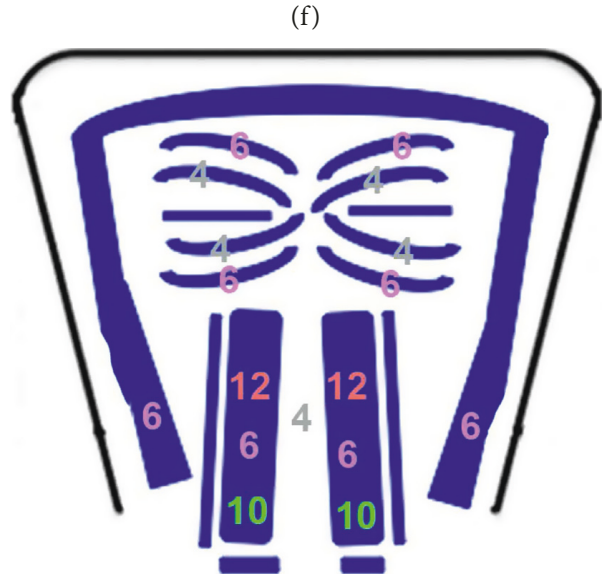

(i)

FIGURE 7: Summary of expression of Sox genes in tongue mesenchyme and muscle during development. Diagrammatic representation of developing tongue of the anterior (a), (d), (g); middle (b), (e), (h); and posterior region (c), (f), (i) at E12 (a-c), E13 (d-f), and E14 (g-i). The muscle is shown in blue. The numbers represent each Sox gene. Sox genes showing ubiquitous expression are excluded. 


\section{Data Availability}

The data used to support the findings of this study are included within the article.

\section{Conflicts of Interest}

All authors declare no potential conflicts of interest with respect to the authorship and/or publication of this article.

\section{Acknowledgments}

This research was funded by the Japan Society for the Promotion of Science (JSPS; 17H01601).

\section{References}

[1] D. M. Noden and P. Francis-West, "The differentiation and morphogenesis of craniofacial muscles," Developmetal Dynamics, vol. 235, no. 5, pp. 1194-1218, 2006.

[2] C. Parada, D. Han, and Y. Chai, "Molecular and cellular regulatory mechanisms of tongue myogenesis," Journal of Dental Research, vol. 91, no. 6, pp. 528-535, 2012.

[3] C. Parada and Y. Chai, "Mandible and Tongue Development," Current Topics in Developmental Biology, vol. 115, pp. 31-58, 2015.

[4] M. T. Cobourne, S. Iseki, A. A. Birjandi et al., "How to make a tongue: Cellular and molecular regulation of muscle and connective tissue formation during mammalian tongue development," Seminars Cell and Developmental Biology, 2018, In press.

[5] L. H. Pevny and R. Lovell-Badge, "Sox genes find their feet," Current Opinion in Genetics and Development, vol. 7, no. 3, pp. 338-344, 1997.

[6] Z. Y. She and W. X. Yang, "SOX family transcription factors involved in diverse cellular events during development," European Journal of Cell Biology, vol. 94, no. 12, pp. 547-563, 2015.

[7] K. Kawasaki, M. Kawasaki, M. Watanabe et al., "Expression of Sox genes in tooth development," International Journal of Developmental Biology, vol. 59, no. 10-12, pp. 471-478, 2015.

[8] O. Lioubinski, M. Müller, M. Wegner, and M. Sander, "Expression of Sox transcription factors in the developing mouse pancreas," Developmental Dynamics, vol. 227, no. 3, pp. 402-408, 2003.

[9] H. E. Jackson and P. W. Ingham, "Control of muscle fibretype diversity during embryonic development: the zebrafish paradigm," Mechanisms of Devevelopment, vol. 130, no. 9-10, pp. 447-457, 2013.

[10] S. Lin, X. Lin, Z. Zhang et al., "Copy number variation in Sox6 contributes to chicken muscle development," Genes, vol. 17, no. 9, p. 42, 2018.

[11] S. Alonso-Martin, F. Aurade, D. Mademtzoglou, A. Rochat, P. S. Zammit, and F. Relaix, "SOXF factors regulate murine satellite cell self-renewal and function through inhibition of $\beta$-catenin activity," Elife, vol. 8, p. 7, 2018.

[12] A.P. Meeson, X. Shi, M.S. Alexander et al., "Sox15 and Fhl3 transcriptionally coactivate Foxk1 and regulate myogenic progenitor cells," EMBO Journal, vol. 26, no. 7, pp. 1902-1912, 2007.

[13] R.F. Rajgara, N. Lala-Tabbert, F. Marchildon et al., "SOX7 Is Required for Muscle Satellite Cell Development and Maintenance," Stem Cell Reports, vol. 9, no. 4, pp. 1139-1151, 2017.
[14] T. Okubo, L. H. Pevny, and B. L. Hogan, "Sox2 is required for development of taste bud sensory cells," Genes and Development, vol. 20, no. 19, pp. 2654-2659, 2006.

[15] A. Ohazama, E. B. Johnson, M. S. Ota et al., "Lrp4 modulates extracellular integration of cell signaling pathways in development," PLoS One, vol. 3, no. 12, Article ID e4092, 2008.

[16] M. Francois, P. Koopman, and M. Beltrame, "SoxF genes: key players in the development of the cardio-vascular system," International Journal of Biochemistry and Cell Biology, vol. 42, no. 3, pp. 445-448, 2010.

[17] M. Francois, N. L. Harvey, and B. M. Hogan, "The transcriptional control of lymphatic vascular development," Physiology, vol. 26, no. 3, pp. 146-155, 2011.

[18] M. F. Morini and E. Dejana, "Transcriptional regulation of arterial differentiation via Wnt, Sox, and Notch," Current Opinion in Hematology, vol. 21, no. 3, pp. 229-234, 2014.

[19] S. Creuzet, C. Vincent, and G. Couly, "Neural crest derivatives in ocular and periocular structures," International Journal of Developmental Biology, vol. 49, no. 2-3, pp. 161-171, 2005.

[20] H. Ohuchi, "Wakayama Symposium: Epithelial-mesenchymal interactions in eyelid development," Ocular Surface, vol. 10, no. 4, pp. 212-216, 2012.

[21] Y. Lan and R. Jiang, "Sonic hedgehog signaling regulates reciprocal epithelial-mesenchymal interactions controlling palatal outgrowth," Development, vol. 136, no. 8, pp. 13871396, 2009.

[22] J. Jeong, J. Mao, T. Tenzen, A. H. Kottmann, and A. P. McMahon, "Hedgehog signaling in the neural crest cells regulates the patterning and growth of facial primordial," Genes and Development, vol. 18, no. 8, pp. 937-951, 2004.

[23] A. Zehir, L. L. Hu, E. L. Maska, Y. Morikawa, and P. Cserjesi, "Dicer is required for survival of differentiating neural crest cells," Developmental Biology, vol. 340, no. 2, pp. 459-467, 2010.

[24] T. Huang, Y. Liu, M. Huang, X. Zhao, and L. Cheng, "Wnt1cre-mediated conditional loss of Dicer results in malformation of the midbrain and cerebellum and failure of neural crest and dopaminergic differentiation in mice," Journal of Molelular Cell Biology, vol. 2, no. 3, pp. 152-163, 2010.

[25] X. Nie, Q. Wang, and K. Jiao, "Dicer activity in neural crest cells is essential for craniofacial organogenesis and pharyngeal arch artery morphogenesis," Mechanisms of Development, vol. 128, no. 3-4, pp. 200-207, 2011.

[26] T.I. Prigozy, K. Dalrymple, C. Shuler, and L. Kedes, "Differential expression of troponin $\mathrm{C}$ genes during tongue myogenesis," Developmental Dynamics, vol. 209, no. 1, pp. 36-44, 1997.

[27] A. J. Sokoloff, "Localization and contractile properties of intrinsic longitudinal motor units of the rat tongue," Journal of Neurophysiology, vol. 84, no. 2, pp. 827-835, 2000.

[28] I. Sanders, L. Mu, A. Amirali, H. Su, and S. Sobotka, "The human tongue slows down to speak: muscle fibers of the human tongue," Anatomical Record, vol. 296, no. 10, pp. 1615-1627, 2013.

[29] R. Diogo, R.G. Kelly, L. Christiaen et al., "A new heart for a new head in vertebrate cardiopharyngeal evolution," Nature, vol. 520, no. 7548, pp. 466-473, 2015.

[30] A. Yamane, "Embryonic and postnatal development of masticatory and tongue muscles," Cell and Tissue Research, vol. 322, no. 2, pp. 183-189, 2005.

[31] H. Aoyagi, S. Iwasaki, and T. Asami, "Three-Dimensional Architecture of the Mouse Tongue Muscles Using Micro-CT with a Focus on the Transverse, Vertical, and Genioglossus Muscles," Surgical Science, vol. 6, no. 8, pp. 358-368, 2015. 
[32] R. Hosokawa, K. Oka, T. Yamaza et al., "TGF-beta mediated FGF10 signaling in cranial neural crest cells controls development of myogenic progenitor cells through tissue-tissue interactions during tongue morphogenesis," Developmental Biology, vol. 341, no. 1, pp. 186-195, 2010.

[33] G. F. Couly, P. M. Coltey, and N. M. Le Douarin, "The developmental fate of the cephalic mesoderm in quail-chick chimeras," Development, vol. 114, no. 1, pp. 1-15, 1992.

[34] D. J. Evans and D. M. Noden, "Spatial relations between avian craniofacial neural crest and paraxial mesoderm cells," Developmental Dynamics, vol. 235, no. 5, pp. 1310-1325, 2006.

[35] Y. Aoki, N. Saint-Germain, M. Gyda et al., "Sox10 regulates the development of neural crest-derived melanocytes in Xenopus," Developmental Biolology, vol. 259, no. 1, pp. 19-33, 2003.

[36] T. Suzuki, D. Sakai, N. Osumi, H. Wada, and Y. Wakamatsu, "Sox genes regulate type 2 collagen expression in avian neural crest cells," Development, Growth and Differentiation, vol. 48, no. 8, pp. 477-486, 2006.

[37] M. Cheung and J. Briscoe, "Neural crest development is regulated by the transcription factor Sox9," Development, vol. 130, no. 23, pp. 5681-5693, 2003.

[38] Y. Asou, A. Nifuji, K. Tsuji et al., "Coordinated expression of scleraxis and Sox9 genes during embryonic development of tendons and cartilage," Journal Orthopaedic Research, vol. 20, no. 4, pp. 827-833, 2002.

[39] L. Le Guen, S. Marchal, S. Faure, and P. de Santa Barbara, "Mesenchymal-epithelial interactions during digestive tract development and epithelial stem cell regeneration," Cellular and Molecular Life Science, vol. 72, no. 20, pp. 3883-3896, 2015.

[40] S. Yasugi and K. Fukuda, "The mesenchymal factors regulating epithelial morphogenesis and differentiation of the chicken stomach," Zoological Science, vol. 17, no. 1, pp. 1-9, 2000 . 


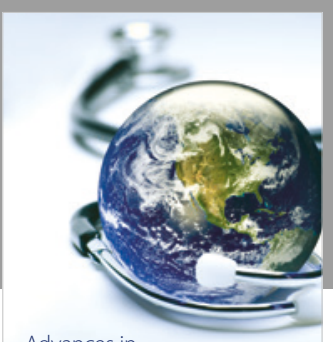

Advances in
Public Health

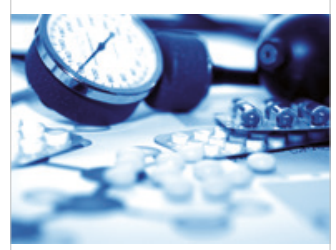

Case Reports in

Medicine

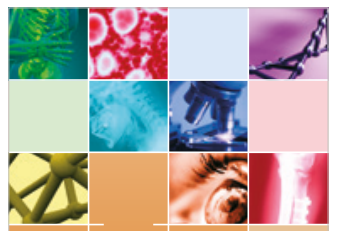

niernational Journal of

Biomaterials
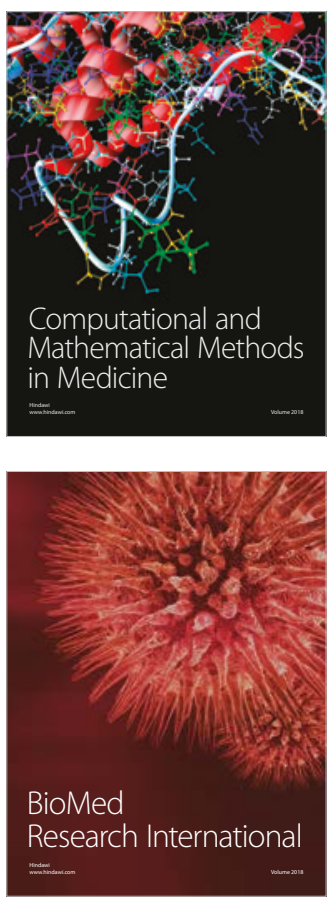

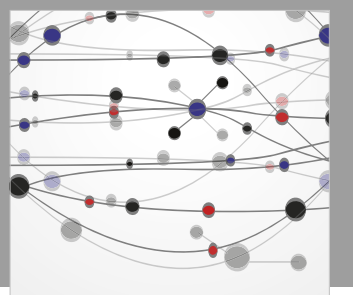

The Scientific World Journal Dentistry

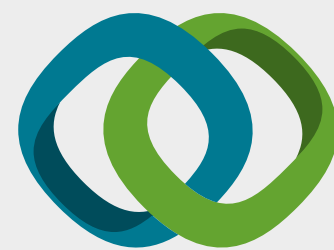

Hindawi

Submit your manuscripts at

www.hindawi.com
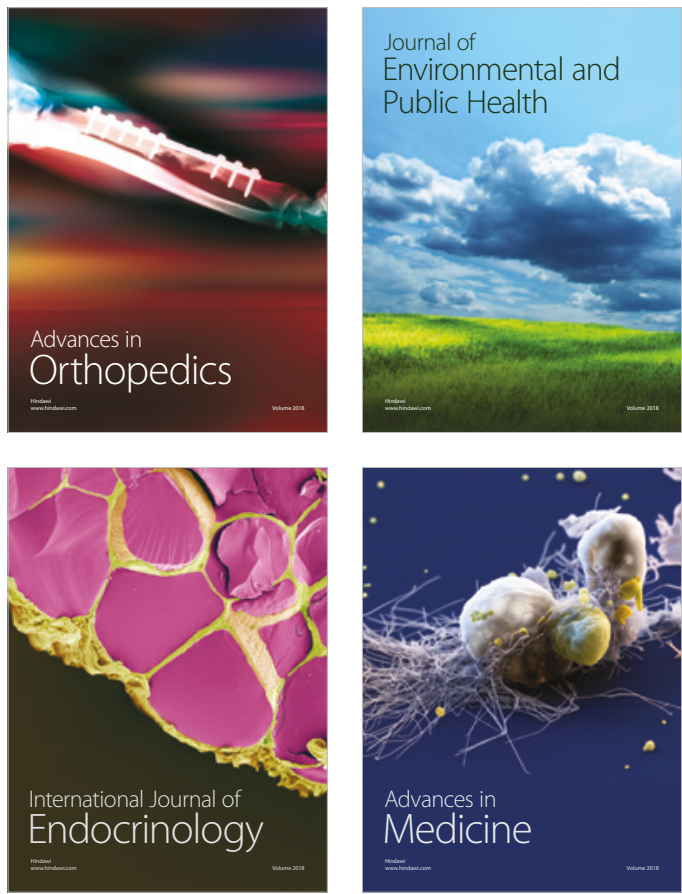
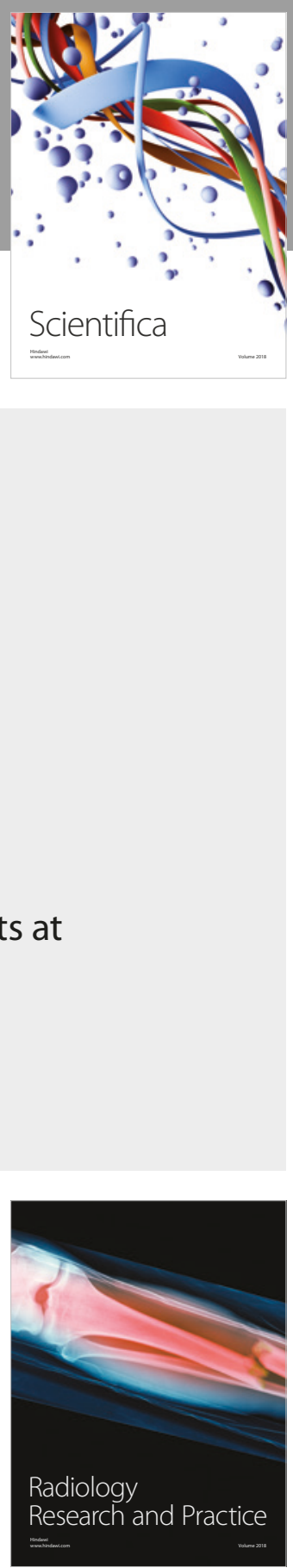

Scientifica

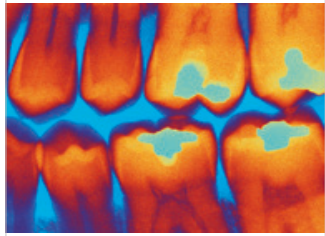

Case Reports in

Dentistry
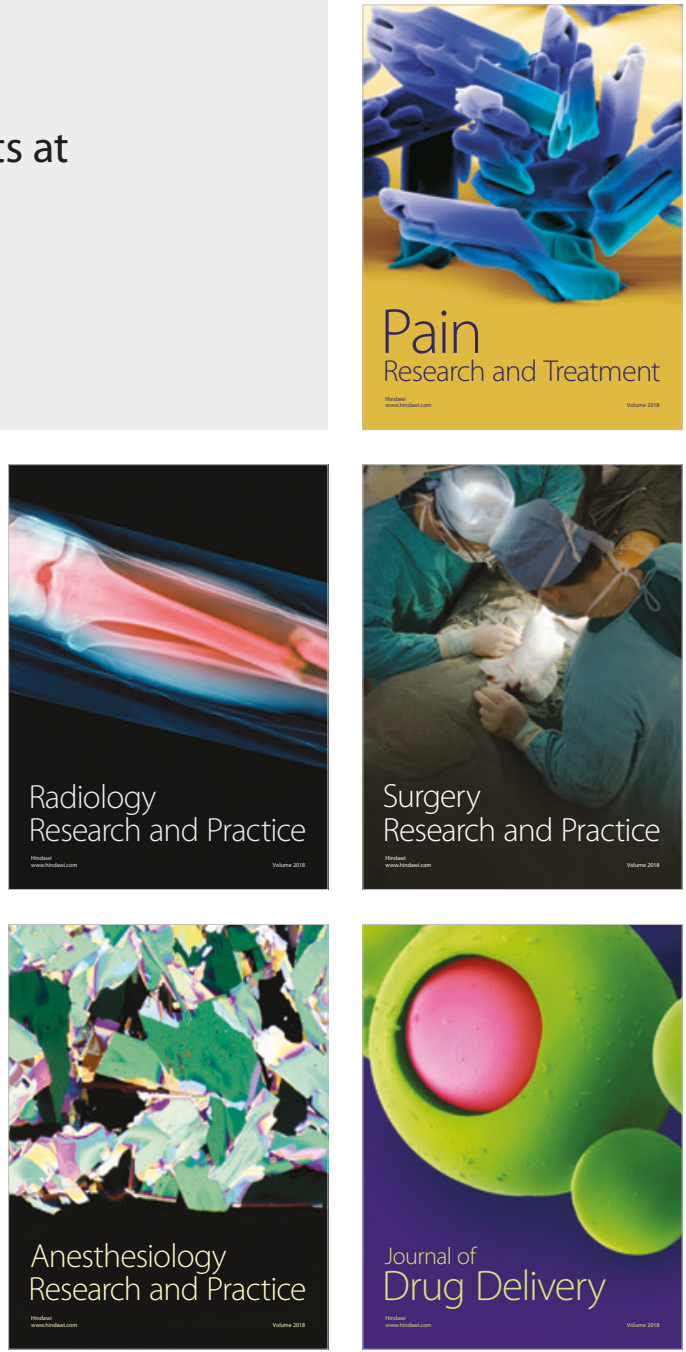